\title{
Gastrointestinal hemorrhage before anticoagulant therapy in Kawasaki disease: a case report
}

\author{
Chenmin Hu(D) and Yanping $\mathrm{Yu}^{*}$
}

\begin{abstract}
Background: Kawasaki disease (KD) is an acute febrile multisystem vasculitis and has been recognized to be the most common cause of acquired heart disease in children. Owing to its propensity to involve vessels throughout the entire body, KD often mimics other disease processes. The diagnosis might be delayed if other prominent symptoms appear before the characteristic clinical features of KD. Although gastrointestinal symptoms including vomiting, diarrhea, and abdominal pain are not uncommon in KD patients, KD with gastrointestinal bleeding is quite rare.
\end{abstract}

Case presentation: A previously healthy 4-year-old boy initially presented with abdominal pain, followed by fever, rash, and gastrointestinal hemorrhage, eventually diagnosed as complete KD. The patient recovered smoothly after appropriate management and no subsequent complications occurred in the following months.

Conclusion: The diagnosis of KD should be considered in children presenting with abdominal symptoms and fever without definable cause. Pediatricians should be aware of the risk of gastrointestinal bleeding in patients with KD, especially in those with prominent abdominal symptoms.

Keywords: Kawasaki disease, Gastrointestinal hemorrhage, Duodenal ulcer, Abdominal pain, Case report

\section{Background}

Kawasaki disease (KD) is an acute febrile multisystem vasculitis of unknown etiology, especially involving coronary arteries, and has been recognized to be the most common cause of acquired heart disease in children [1]. This vasculitis results in exudative change with infiltration of lymphocytes and large mononuclear cells into the media and adventitia of the vessels with endothelial necrosis [1]. Although inflammation of the coronary arteries results in the most important clinical outcomes, these problems of vessels may also occur in many other organs. Although the prevalence of gastrointestinal involvement in KD is unknown, gastrointestinal symptoms including vomiting, diarrhea, and abdominal pain are not uncommon [2]. However, gastrointestinal hemorrhage in patients with $\mathrm{KD}$ is rather rare. Herein, we report a 4-year-old boy with $\mathrm{KD}$ initially presenting with abdominal pain and complicated by

\footnotetext{
* Correspondence: yyp757605@163.com

Department of Pediatrics, Affiliated Hangzhou First People's Hospital,

Zhejiang University School of Medicine, Hangzhou 310006, China
}

gastrointestinal hemorrhage due to duodenal ulcer before the use of aspirin. Favorable outcomes for these patients may depend upon the keen judgment of pediatricians familiar with the disease's presentation and management.

\section{Case presentation}

A previously healthy 4-year-old boy presented with a 5day history of abdominal pain, 4-day history of fever and rash. Five days ago, the boy had a sudden onset of persistent abdominal pain, accompanied by vomiting. Empirically, initial therapy with intravenous antibiotics and cimetidine was performed in local hospital. The next day, fever occurred $\left(39^{\circ} \mathrm{C}-39.8^{\circ} \mathrm{C}\right)$, accompanied by a miliary rash scattered throughout the body. On the third day, the skin rash increased, accompanied by conjunctival hyperemia, erythema and swelling of the hands and feet. The laboratory examinations revealed white blood cell count of $13.14 \times 10^{\wedge} 9 / \mathrm{L}$ with predominance of neutrophil 90.6\%, hemoglobin level of $120 \mathrm{~g} / \mathrm{L}$, platelet count of $204 \times 10^{\wedge} 9 / \mathrm{L}$, and C-reactive protein (CRP) of $101.9 \mathrm{mg} / \mathrm{L}$. Abdominal computed tomography shows

(c) The Author(s). 2020 Open Access This article is distributed under the terms of the Creative Commons Attribution 4.0 International License (http://creativecommons.org/licenses/by/4.0/), which permits unrestricted use, distribution, and reproduction in any medium, provided you give appropriate credit to the original author(s) and the source, provide a link to the Creative Commons license, and indicate if changes were made. The Creative Commons Public Domain Dedication waiver (http://creativecommons.org/publicdomain/zero/1.0/) applies to the data made available in this article, unless otherwise stated. 
the accumulation of gas and fluid in the small intestine. An echocardiography showed no dilatation of coronary arteries. On day $5, \mathrm{He}$ vomited a small amount of coffee-like liquid and discharged a moderate amount of tarry stool. Then, the patient was transferred to our hospital by emergency.

On admission, physical examination revealed an acutely ill boy with fever of $38.5^{\circ} \mathrm{C}$, pulse of 124 times per minute, breathing of 30 times per minute, and blood pressure of $94 / 47 \mathrm{mmHg}$. The boy displayed erythematous maculopapular rash over the body, bilateral conjunctival hyperemia, erythema and swelling of the hands and feet, dry and cracked lips, oropharyngeal hyperemia and mild strawberry tongue. One enlarged lymph node approximately $1.5 \times 1 \mathrm{~cm}$ was palpable in the right anterior cervical triangle. His abdomen was slightly tense with mild tenderness. Laboratory tests are summarized in Table 1. The main abnormalities were as follows: hemoglobin concentration $108 \mathrm{~g} / \mathrm{L}$; white blood cell count $11.5 \times 10^{\wedge} 9 / \mathrm{L}$, neutrophils $91.5 \%$; platelet count $65 \times 10^{\wedge} 9 / \mathrm{L}$; CRP $31 \mathrm{mg} / \mathrm{L}$, serum alanine aminotransferase (ALT) $54 \mathrm{U} / \mathrm{L}$, total protein $37.2 \mathrm{~g} / \mathrm{L}$, albumin $21.3 \mathrm{~g} / \mathrm{L}$, creatine kinase isoenzyme MB (CK-MB) $56 \mathrm{U} /$ $\mathrm{L}$, potassium $3.11 \mathrm{mmol} / \mathrm{L}$, D-Dimer $6230 \mu \mathrm{g} / \mathrm{L}$, fecal occult blood +++. In light of these findings and the clinical features, a diagnosis of KD with upper gastrointestinal bleeding was made. The boy received supportive care and intravenous omeprazole $(0.6 \mathrm{mg} / \mathrm{kg} /$ day $)$. On day 6

Table 1 Laboratory data during acute phase

\begin{tabular}{lllll}
\hline Parameters & Day 3 & Day 5 & Day 8 & Day 12 \\
\hline Leukocytes $(\times 10 \wedge 9 / \mathrm{L})$ & 13.14 & 11.5 & 6.7 & 9.8 \\
Neutrophil $(\%)$ & 90.6 & 91.5 & 40.1 & 57.0 \\
Hemoglobin $(\mathrm{g} / \mathrm{L})$ & 120 & 108 & 102 & 103 \\
Platelet $(\times 10 \wedge 9 / \mathrm{L})$ & 204 & 65 & 115 & 672 \\
C-reactive protein $(\mathrm{mg} / \mathrm{L})$ & 101.9 & 31 & 5 & 3 \\
Total protein $(\mathrm{g} / \mathrm{L})$ & $/$ & 37.2 & 51 & 52.3 \\
Albumin $(\mathrm{g} / \mathrm{L})$ & $/$ & 21.3 & 21.7 & 25.9 \\
Alanine aminotransferase $(\mathrm{U} / \mathrm{L})$ & $/$ & 54 & 19 & 11 \\
Total bilirubin $(\mu \mathrm{mol} / \mathrm{L})$ & $/$ & 6.3 & 6.6 & 5.2 \\
Creatinine $(\mu \mathrm{mol} / \mathrm{L})$ & $/$ & 59 & 47 & 37 \\
Creatine kinase $(\mathrm{U} / \mathrm{L})$ & $/$ & 61 & 39 & 33 \\
Creatine kinase isoenzyme $\mathrm{MB}(\mathrm{U} / \mathrm{L})$ & $/$ & 56 & 27 & 23 \\
Potassium $(\mathrm{mmol} / \mathrm{L})$ & $/$ & 3.11 & 3.59 & 4.47 \\
Sodium $(\mathrm{mmol} / \mathrm{L})$ & $/$ & 131 & 132 & 135 \\
Chlorine $(\mathrm{mmol} / \mathrm{L})$ & $/$ & 99 & 101 & 105 \\
Prothrombin time $(\mathrm{sec})$ & $/$ & 13.3 & 12.5 & $/$ \\
D-Dimer $(\mu \mathrm{s} / \mathrm{L})$ & $/$ & 6230.0 & 1280 & 700.0 \\
Serum amylase $(\mathrm{U} / \mathrm{L})$ & $/$ & 33 & $/$ & $/$ \\
Fecal occult blood & +++ & + & $/$ \\
\hline
\end{tabular}

(the 5th day of fever), a total dose of intravenous immunoglobulin (IVIG, $2 \mathrm{~g} / \mathrm{kg}$ ) was administered. Aspirin was not administered because of his upper gastrointestinal bleeding. After $24 \mathrm{~h}$ of IVIG, his fever began to subside and the skin rash diminished dramatically. On the second day after IVIG, laboratory findings showed a normal leukocytes of $6.7 \times 10^{\wedge} 9 / \mathrm{L}$ and a remarkable fall of the CRP levels at $5 \mathrm{mg} / \mathrm{L}$ and the D-Dimer levels at $1280 \mu \mathrm{g} / \mathrm{L}$ (Table 1). However, the fecal occult blood continued to be positive although his gastrointestinal symptoms were improved.

An endoscopy was performed on Day 8 of illness. We found an active ulcer covered with thick "white moss" in duodenal bulb (Fig. 1). Then, the dose of intravenous omeprazole was increased to $0.8 \mathrm{mg} / \mathrm{kg} /$ day. Repeated echocardiography on Day 9 demonstrated a mild dilatation of the left coronary artery $(2.8$ $\mathrm{mm})$. Oral clopidogrel $(1 \mathrm{mg} / \mathrm{kg} /$ day $)$ was added to treatment. On day 10, 13C-urea breath test showed that his helicobacter pylori status was negative. On day 12 , most of the laboratory parameters were normal or close to normal except for elevated platelet count of $672 \times 10^{\wedge} 9 / \mathrm{L}$. The next day, he was discharged and continued with oral omeprazole $(0.6 \mathrm{mg} / \mathrm{kg} /$ day $)$ for 4 weeks and clopidogrel $(1 \mathrm{mg} / \mathrm{kg} /$ day $)$ for a further 8 weeks. Follow-up at 1 month after discharge revealed no recurrence of fever or remarkable abdominal pain. Repeated echocardiography at 8 weeks after discharge revealed that the dilated left coronary artery regressed to normal. A 1 year follow-up showed no cardiac involvement or other complications.

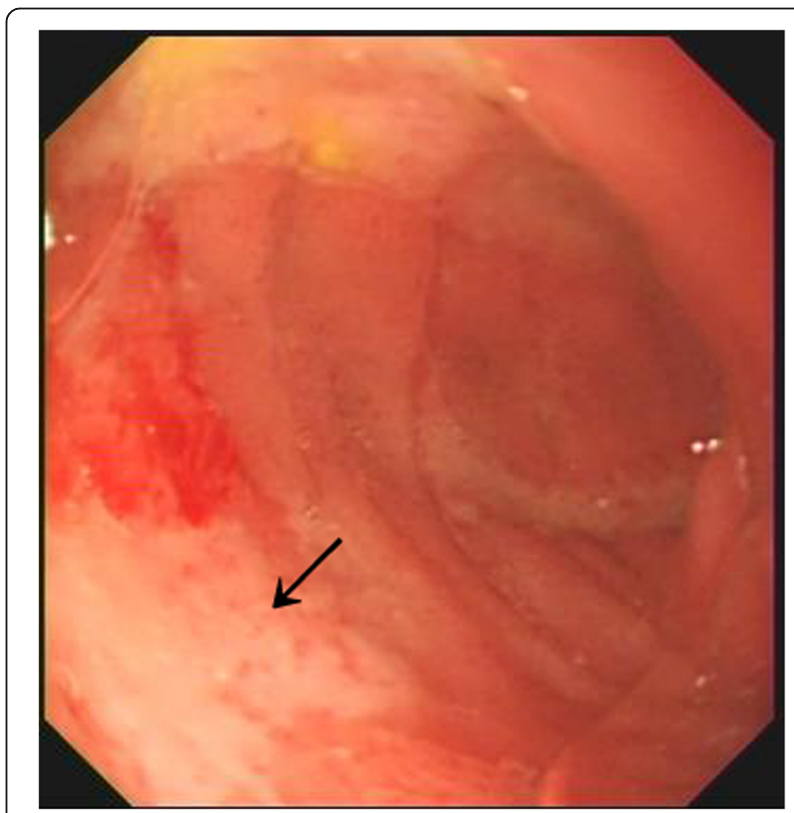

Fig. 1 Gastroscopy results showing an active ulcer covered with thick "white moss" in duodenal bulb 


\section{Discussion}

$\mathrm{KD}$ is the most common vasculitis in children [3]. Even though more than 50 years have passed since the first description of this disease, the diagnosis of KD continues to remain a clinical dilemma and there is no confirmatory laboratory test [4]. The diagnosis of $\mathrm{KD}$ is based on the presence of fever (lasting $>5$ days) together with 4 of the 5 characteristic diagnostic criteria (rash, oropharyngeal changes, non-purulent conjunctivitis, cervical lymphadenopathy and change of the extremities) [1, 4]. A prompt diagnosis is crucial because prognosis relies on timely initiation of the optimal treatment. The most common and life-threatening complication of KD, coronary artery abnormalities (CAA), will occur in approximately $25 \%$ of untreated patients which may lead to death by causing coronary thrombosis or myocardial infarction. The delayed diagnosis of KD could result in life-threatening problems particularly including cardiovascular sequelae.

Owing to its propensity to involve the medium-sized arteries in multiple organs, KD often mimics other disease processes. The diagnosis might be delayed if other prominent symptoms appear before the characteristic clinical features of KD, especially in children with incomplete or atypical forms. Incomplete KD occurs in patients presenting a typical fever without a sufficient number of main clinical criteria, with or without CAA. This kind of KD is frequent in children younger than 12-24 months and should be considered in the differential diagnosis of prolonged unexplained fever in childhood associated with any of the characteristic clinical features of the disease [1]. The diagnosis can be considered confirmed when coronary artery aneurysms are identified in such patients by echocardiography. However, coronary artery dilatation is generally not detected by echocardiography until after the first week of illness, and a normal echocardiogram in the first week of illness does not rule out the diagnosis of KD. The term atypical $\mathrm{KD}$ is used when there are one or more symptoms or signs different from the main KD clinical features such as pneumonia, meningoencephalitis, facial paralysis, acute abdomen, arthritis, cholestatic jaundice, and renal injury [5]. The diagnosis of KD is more challenging in the presence of one or more atypical manifestations.

The prevalence of gastrointestinal involvement in KD is unknown as available data can only be derived from single case and case series. Zulian et al. in their case series reported an incidence of atypical KD with a clinical onset characterized by acute abdomen of $4.6 \%$ [6]. Gastrointestinal symptoms at KD onset can complicate clinical recognition, lead to unnecessary invasive interventions and cause therapeutic delay, thus increasing the risk of cardiac complications [2]. A retrospective multicenter report from Italy demonstrated that presenting gastrointestinal symptoms in KD identify patients at higher risk for IVIG-resistance and for the development of coronary aneurysms [7]. Therefore, the diagnosis of KD should be considered in children with gastrointestinal symptoms and prolonged fever without clear cause.

Our patient presented with abdominal pain at the onset of disease. Fortunately, the followed fever, rash and other typical signs of KD led to timely diagnosis and treatment. Although laboratory tests are nonspecific, they can provide support for a diagnosis of $\mathrm{KD}$ in patients with suggestive clinical features. For our patients, laboratory tests supporting KD diagnosis included changes of markers at acute phase such as leukocytosis, elevated CRP, hypoalbuminemia, mild elevations of ALT, and mild elevations of CK-MB and thrombocytosis on day 12 of illness. Thrombocytosis is a characteristic feature of KD but generally does not occur until the second week, peaking in the third week and normalizing by 4 to 6 weeks after onset in most cases $[1,5]$. In addition, thrombocytopenia and elevations of D-Dimer in our patient were detected in the first week of illness. Although uncommon, thrombocytopenia in acute phase of KD may be a sign of disseminated intravascular coagulation and is a risk factor for the development of coronary artery abnormalities.

The mechanism of gastrointestinal involvement at the onset of KD has not yet been clarified. The possible explanation is that gastrointestinal tract is the first organ involved with systemic vasculitis of the medium-sized arteries, leading to abdominal pain and vomiting. However, the etiology and the entire pathophysiology of KD remain elusive, despite a host of data supports the notion that the pathogenesis of $\mathrm{KD}$ is closely associated with dysregulation of immune responses to infectious agents $[8,9]$. The gastrointestinal tract has been proposed as a major site of entry of infectious agents that might act as superantigens, even though more recent studies have favored a canonical response to a conventional antigen [1]. Recently, an increasing number of studies have focused on the contribution of gut microbiota to KD. Esposito et al. postulated that an imbalance in the gut microbiota might indirectly interfere with the normal function of immunity, and that variable microbiota interactions with environmental factors, mainly infectious agents, might selectively drive the development of KD in genetically susceptible children [10].

Compared to the frequently reported gastrointestinal symptoms, KD with gastrointestinal hemorrhage is quite rare. Only 5 previous cases have been documented in the English literature, as showed in Table 2. Two cases of severe gastrointestinal hemorrhage complicating highdose aspirin therapy were iatrogenic [11]. Zulian et al. reported a 20-month-old KD boy who had sudden onset of hematemesis without aspirin and presented with 
Table 2 Clinical characteristics of the reported patients with gastrointestinal hemorrhage in Kawasaki disease

\begin{tabular}{|c|c|c|c|c|c|c|c|}
\hline Year & First author & Age/sex & Clinical onset & $\begin{array}{l}\text { Details of gastrointestinal } \\
\text { bleeding }\end{array}$ & $\begin{array}{l}\text { Blood } \\
\text { transfusion }\end{array}$ & Endoscopy & Surgery \\
\hline 1996 & Matsubara & $2 y / M$ & Fever & $\begin{array}{l}\text { Hematemesis on day } 19 \text { of } \\
\text { illness (day } 13 \text { of aspirin) }\end{array}$ & Yes & $\begin{array}{l}\text { Revealed a } 2 \mathrm{~cm} \\
\text { duodenal ulcer }\end{array}$ & None \\
\hline 1996 & Matsubara & $4 \mathrm{y} / \mathrm{F}$ & Fever & $\begin{array}{l}\text { Melanotic stools followed by } \\
\text { emesis of blood on day } 31 \\
\text { of illness (day } 26 \text { of aspirin) }\end{array}$ & Yes & None & None \\
\hline 2003 & Zulian & $20 \mathrm{~m} / \mathrm{M}$ & Fever & $\begin{array}{l}\text { Hematemesis on day } 7 \text { of } \\
\text { illness without aspirin }\end{array}$ & Yes & $\begin{array}{l}\text { Showed diffuse } \\
\text { hemorrhagic } \\
\text { duodenitis }\end{array}$ & None \\
\hline 2004 & Chang & $5 \mathrm{y} / \mathrm{M}$ & $\begin{array}{l}\text { Fever, cervical } \\
\text { lymphadenitis }\end{array}$ & $\begin{array}{l}\text { Tarry stool on day } 6 \\
\text { of illness; } \\
\text { Massive gastrointestinal } \\
\text { bleeding on day } 14 \text { of } \\
\text { illness (day } 5 \text { of aspirin) }\end{array}$ & Yes & NA & NA \\
\hline 2007 & Singh & $4.5 \mathrm{y} / \mathrm{M}$ & $\begin{array}{l}\text { Nausea, vomiting, } \\
\text { diarrhea and fever }\end{array}$ & $\begin{array}{l}\text { Hemorrhagic shock } \\
\text { with hematemesis and } \\
\text { hematochezia at } 2 \text { months } \\
\text { after onset (without aspirin) }\end{array}$ & Yes & $\begin{array}{l}\text { Failed because of } \\
\text { the massive bleeding }\end{array}$ & $\begin{array}{l}\text { Revaeled a } 1.5 \mathrm{~cm} \\
\text { duodenal ulcer with } \\
\text { active bleeding }\end{array}$ \\
\hline
\end{tabular}

diffuse hemorrhagic duodenitis by endoscopy [6]. Singh et al. reported a 4.5-year-old KD boy who developed hemorrhagic shock and revealed a duodenal ulcer with active bleeding by surgery [12]. Chang et al. reported a 5 -year-old KD boy who had tarry stool on day 6 of fever. Three days later, he was still treated with high-dose aspirin and massive gastrointestinal bleeding occurred on day 5 of aspirin treatment [13].

Before the definitive diagnosis of KD, our patient developed upper gastrointestinal bleeding confirmed by the subsequent endoscopy. On day 5 of fever, he received intravenous immunoglobulin and omeprazole but not high-dose aspirin. The iatrogenic second bleeding as in Chang's case was avoided. Generally, when high-dose aspirin is discontinued after KD patient has been afebrile for 48 to $72 \mathrm{~h}$, low-dose aspirin $(3-5 \mathrm{mg} / \mathrm{kg} / \mathrm{d})$ should be started and continued until the patient has no evidence of coronary changes by 6 to 8 weeks after onset of illness. For children who develop coronary abnormalities, aspirin may be continued indefinitely. Clopidogrel (0.2$1 \mathrm{mg} / \mathrm{kg} / \mathrm{d}$ ) can be used in place of low-dose aspirin for patients who are aspirin resistant or allergic to aspirin [1]. For our patient, aspirin may have a higher risk of aggravating duodenal ulcer. As an alternative anticoagulant therapy, clopidogrel was started and continued for 8 weeks after discharge when a mild dilatation of coronary artery was revealed on day 9 of illness. Finally, our patient completely recovered.

IVIG and aspirin were considered as the standard initial treatment of KD for decades. The efficacy of IVIG administered in the acute phase of KD is well established to reduce the prevalence of CAA [1]. However, the role of high-dose aspirin in KD remains controversial. Kuo et al. demonstrated that high-dose aspirin in KD did not confer any benefit with regards to inflammation and it did not appear to improve treatment outcomes [14]. A recent meta-analysis revealed that low-dose aspirin (3-5 $\mathrm{mg} / \mathrm{kg} / \mathrm{d}$ ) may be as effective as the use of high-dose aspirin (>30 mg/kg/d) for the initial treatment of KD [15]. Accordingly, we believe that high-dose aspirin may be unnecessary in $\mathrm{KD}$ with prominent gastrointestinal symptoms. However, further well-designed prospective studies are still required to evaluate the efficacy of lowdose aspirin for KD.

\section{Conclusions}

The diagnosis of KD should be considered in children presenting with abdominal symptoms and fever without definable cause. Pediatricians should be aware of the risk of gastrointestinal bleeding in patients with KD, especially in those with prominent abdominal symptoms.

\section{Abbreviations}

ALT: Alanine aminotransferase; CAA: Coronary artery abnormalities; CKMB: Creatine kinase isoenzyme MB; CRP: C-reactive protein; IVIG: Intravenous immunoglobulin; KD: Kawasaki disease

\section{Acknowledgements}

Not applicable.

\section{Authors' contributions}

YY designed the work and drafted the manuscript. CH collected literatures and was a major contributor in writing the manuscript. Both authors read and approved the final manuscript.

\section{Funding}

This work did not receive funding.

\section{Availability of data and materials}

The datasets used and/or analyzed during the current study are available from the corresponding author on reasonable request. 


\section{Ethics approval and consent to participate}

The study protocol was approved by the Ethics Commission of Affiliated Hangzhou First People's Hospital, Zhejiang University School of Medicine. Permission to carry out the study and access patient records was sought from the respective hospital administrators.

\section{Consent for publication}

Written consent for publication of this anonymous information was obtained from the patient's parents and the proof of consent can be requested at any time.

\section{Competing interests}

The authors declare that they have no competing interests.

Received: 17 October 2019 Accepted: 7 January 2020

Published online: 27 January 2020

\section{References}

1. McCrindle BW, Rowley AH, Newburger JW, et al. Diagnosis, treatment, and long-term Management of Kawasaki Disease: a scientific statement for health professionals from the American Heart Association. Circulation. 2017; 135(17):e927-99.

2. Colomba C, La Placa S, Saporito L, et al. Intestinal Involvement in Kawasaki Disease. J Pediatr. 2018;202:186-93.

3. Singh S, Vignesh P, Burgner D. The epidemiology of Kawasaki disease: a global update. Arch Dis Child. 2015;100(11):1084-8.

4. Singh S, Jindal AK, Pilania RK. Diagnosis of Kawasaki disease. Int J Rheum Dis. 2018;21:36-44

5. Marchesi A, Tarissi de Jacobis I, Rigante D, et al. Kawasaki disease: guidelines of the Italian Society of Pediatrics, part I - definition, epidemiology, etiopathogenesis, clinical expression and management of the acute phase. Ital J Pediatr. 2018;44(1):102.

6. Zulian F, Falcini F, Zancan L, et al. Acute surgical abdomen as presenting manifestation of Kawasaki disease. J Pediatr. 2003;142:731-5.

7. Fabi M, Corinaldesi E, Pierantoni L, et al. Gastrointestinal presentation of Kawasaki disease: a red flag for severe disease? PLoS One. 2018;13(9): e0202658.

8. Principi N, Rigante D, Esposito S. The role of infection in Kawasaki syndrome. J Inf Secur. 2013;67(1):1-10.

9. Nakamura A, Ikeda K, Hamaoka K. Aetiological significance of infectious stimuli in Kawasaki disease. Front Pediatr. 2019;7:244.

10. Esposito S, Polinori I, Rigante D. The gut microbiota-host partnership as a potential driver of Kawasaki syndrome. Front Pediatr. 2019;7:124.

11. Matsubara T, Mason W, Kashani IA, Kligerman M, Burns JC. Gastrointestinal hemorrhage complicating aspirin therapy in acute Kawasaki disease. J Pediatr. 1996:128:701-3.

12. Singh $\mathrm{R}$, Ward $\mathrm{C}$, Walton $M$, et al. Atypical Kawasaki disease and gastrointestinal manifestations. Paediatr Child Health. 2007:12:235-7.

13. Chang $\mathrm{CH}$, Chen $\mathrm{MH}$, Yang W. Kawasaki disease presenting with lymphadenopathy and gastrointestinal hemorrhage: report of one case. Acta Paediatr Taiwan. 2004;45:171-3.

14. Kuo HC, Lo MH, Hsieh KS, Guo MM, Huang YH. High-Dose Aspirin is Associated with Anemia and Does Not Confer Benefit to Disease Outcomes inKawasaki Disease. PLoS One. 2015;10:e0144603.

15. Zheng $X$, Yue P, Liu L, et al. Efficacy between low and high dose aspirin for the initial treatment of Kawasaki disease: Current evidence based on a meta-analysis. PLoS One. 2019;14:e0217274.

\section{Publisher's Note}

Springer Nature remains neutral with regard to jurisdictional claims in published maps and institutional affiliations.

Ready to submit your research? Choose BMC and benefit from:

- fast, convenient online submission

- thorough peer review by experienced researchers in your field

- rapid publication on acceptance

- support for research data, including large and complex data types

- gold Open Access which fosters wider collaboration and increased citations

- maximum visibility for your research: over $100 \mathrm{M}$ website views per year

At $\mathrm{BMC}$, research is always in progress.

Learn more biomedcentral.com/submissions 